\title{
HALLOWEEN, HISTÓRIAS DE BRUXAS E LENDAS BRASILEIRAS: UMA EXPERIÊNCIA DE LEITURA, PRODUÇÃO TEXTUAL E BRINCADEIRAS NA ESCOLA
}

\section{HALLOWEEN, WITCHES, AND BRAZILIAN LEGENDS: A READING EXPERIENCE, TEXTUAL PRODUCTION, AND ENTERTAINMENT AT SCHOOL}

\section{Anilse Maria Picollo Borttolin ${ }^{1}$}

Resumo: Este trabalho pretende expor uma significativa prática de ensino realizada com os estudantes do ensino fundamental II, a partir de leitura de histórias sobre bruxas e lendas brasileiras; produção textual e brincadeiras; prática esta capaz de contribuir para disseminar uma cultura de cooperação entre eles e torná-los sujeitos participativos e capazes de reconhecer a sua importância na sociedade. Durante o percurso, observouse que os estudantes conseguiram relacionar as histórias lidas, manifestando sentimentos, experiências, opiniões, definindo preferência e construindo critérios próprios para selecionar o que querem ler e, inclusive, produzindo os próprios textos e encaminhando-os aos colegas de outras séries na escola. A abordagem teórica vincula-se às reflexões de Bakhtin (2002) e (2003), Soares (2004), Pacheco (2004) e Perrone-Moisés (2003) e, levando em consideração, também, documentos educacionais, a exemplo dos PCNs (1997) e (1998).

Palavras-chave: textos literários; leitura; produção textual.

Abstract: This paper discusses about an important exercise for teaching elementary school students, by reading fiction stories about witches and Brazilian legends; textual production and games. This exercise can help disseminate a culture of cooperation between students and make them participate in the subject and able to recognize its importance in society. During the course, it was observed that the students were able to relate to the stories read. They were able to express feelings, experiences, opinions, preferences, and build their own rules to select what they want to read and produce their own texts. Then the students presented them to colleagues of other grades in the school. The theoretical approach is related to reflections of Bakhtin (2002) and (2003), Soares (2004), Pacheco (2004), and Perrone-Moisés (2003) taking into consideration education documents like the PCN (1997) and (1998).

Keywords: food literacy texts; reading; textual production.

\footnotetext{
${ }^{1}$ Mestra em Educação - Universidade do Extremo Sul Catarinense - UNESC, Brasil. Professora de Língua Inglesa e Portuguesa - Escola de Educação Básica Natálio Vassoler, Brasil. E-mail: nicepicollo@hotmail.com.
} 


\section{INTRODUÇÃO}

A presente experiência de leitura, produção textual e brincadeiras na escola objetiva levar ao conhecimento do estudante a cultura do Halloween, disseminar o interesse pela leitura de histórias de bruxas e lendas brasileiras, a escrita de narrativas, bem como a troca de informações com as outras turmas de estudantes da escola. Salienta-se que este é um trabalho promotor de interação social no ambiente escolar.

É preciso proporcionar aos estudantes condições à leitura de histórias em que eles possam vivenciá-las facilmente. Ou seja, desenvolver, também, habilidades que vão além da simples compreensão de um texto, pois é preciso aproximar o ensino e a prática de leitura literária ao contexto desses estudantes.

Sabe-se que a leitura é uma prática social e também um direito de todo cidadão. Para tanto, é importante que e a escola se preocupe com tal prática e que o professor seja um mediador nesse ato. Isto é evidente, pois, de acordo com os Parâmetros Curriculares Nacionais (BRASIL, 1997), o professor que desempenha tal mediação poderá ampliar os limites que o estudante possui entre aquilo que lê e o que vivencia. Este documento também descreve que, com ajuda do professor nesse ato, o estudante poderá entender melhor que a leitura leva a viver experiências diferenciadas, bem como adquirir outros conhecimentos: "só poderá ser realizada com a ajuda do professor, que deverá colocar-se na situação de principal parceiro, agrupar seus estudantes a fim de favorecer a circulação de informações entre eles..." (PCNs, p. 56).

É indispensável que o professor seja muito ativo na sala de aula e que proponha aos estudantes uma relação com o texto para além da simples nomenclatura "Formação de leitores", pois, para Soares (2004b), o professor não deve se empenhar só com a formação de leitores e com atitudes positivas em relação à leitura, mas com uma ideia de leitura como possibilidade de democratização do ser humano, consciente de que sempre há uma relação social entre leitor e autor.

Para tanto, isso requer práticas de leitura de várias maneiras, porque o aprendizado da leitura é uma experiência contínua que se materializa no contato com as diferentes narrativas e no encontro entre o eu e o outro. Nesse caso, é preciso agir alternando papéis sociais numa constante interação e que mobilize a cultura da cooperação.

Segundo Bakhtin (2002), as pessoas vivem de acordo com as relações sociais e se constroem a partir da aproximação entre o "eu" e o "outro". Nessa perspectiva, compreendese que a linguagem se consolida pelo diálogo, e a interação entre as pessoas se efetua. Entende-se, portanto, que a linguagem é significativa e nasce do coletivo, partindo, assim, de um diálogo que vai se formando diariamente.

Trazendo essa ideia para a prática da leitura literária na escola, pode-se dizer que esse ato torna a experiência mais dialógica, e a relação construída nesse meio é capaz de levar o estudante a perceber sua relevância na sociedade. 
Pode-se afirmar que é pela leitura que os estudantes podem compreender a sua experiência no contexto em que vivem. Soares (2004a) nos leva a perceber que a literatura é um meio que encaminha o leitor a ser democrático culturalmente: "a leitura literária democratiza o ser humano porque mostra o homem e a sociedade em sua diversidade e complexidade e, assim, nos torna mais compreensivos, mais tolerantes - compreensão e tolerância são condições essenciais para a democracia cultural". A autora ainda acrescenta que:

[a] leitura literária democratiza o ser humano porque elimina barreiras de tempo e de espaço, mostra que há tempos para além do nosso tempo, que há lugares, povos e culturas para além da nossa cultura, e assim nos torna menos pretensiosos, menos presunçosos - o sentido da relatividade e da pequenez de nosso tempo e lugar é condição essencial para a democracia cultural (2004a, p. 31-32).

Vale ressaltar que a prática da leitura de um texto leva o estudante a escrever outros textos a partir da sua interação na sala de aula, pois o leitor participa do processo com toda a sua experiência de vida e de linguagem, num contexto que ele mesmo formula nas relações sociais.

Partindo das ideias acima e de sugestões feitas pelos estudantes da turma 809, período vespertino, para se comemorar o Halloween na escola, um grupo de professores da Escola de Educação Básica Natálio Vassoler situada no Bairro Vila Franca do município de Forquilhinha - SC. planejaram momentos de leitura e produção textual aos estudantes dessa unidade durante os meses de agosto, setembro, outubro/2013, bem como brincadeiras, no dia 31-10-2013, na escola.

A proposta foi construída com o intuito de promover uma experimentação da leitura literária pelo hábito de ouvir histórias e manifestar suas experiências e opiniões sobre os materiais escritos. Isto é, participar de situações de leitura e de escrita de forma cooperativa, entre os estudantes da escola, a partir de um conhecimento sobre uma cultura estrangeira, como o Halloween.

Para tanto, o objetivo principal deste trabalho é descrever uma significativa prática de ensino realizada com estudantes do ensino fundamental II, a partir da leitura de histórias sobre bruxas e lendas brasileiras; produção textual e brincadeiras, prática esta capaz de contribuir para disseminar uma cultura de cooperação entre eles e torná-los sujeitos participativos e capazes de reconhecer a sua importância na sociedade.

\section{LEITURA LITERÁRIA E COOPERAÇÃO}

Esta experiência de leitura literária e produção textual na escola se ajusta ao eixo temático que compreende a cultura da cooperação que propõe estimular o entendimento mútuo, solidariedade e a cooperação entre as pessoas, reconhecendo que todo envolvimento humano ocorre pelas relações sociais e que é possível promover, com a prática da leitura, produção textual e brincadeiras a partir de um motivo solicitado pelos 
estudantes: festejar o dia do Halloween na escola.

Pode-se dizer que o caráter social da linguagem circula em diversas esferas sociais, utilizando-a de maneiras diferentes, porém com formas típicas de enunciados, que são os gêneros do discurso. $E$ mesmo que eles sejam dinâmicos e vivos, eles também possuem características comuns.

Em se tratando especificamente do gênero histórias de bruxas, da esfera literária, primeiramente buscou-se saber qual é o tratamento dado pelos Parâmetros Curriculares Nacionais aos textos literários para o Ensino Fundamental, uma vez que a escolha dos livros didáticos é feita em nível de federação. Segundo os PCNs (1998, p.37):

É importante que o trabalho com o texto literário esteja incorporado à prática cotidiana da sala de aula, visto tratar-se de uma forma específica de conhecimento. A questão do ensino de literatura ou da leitura literária envolve, portanto, esse exercício de reconhecimento das singularidades e das propriedades compositivas que matizam um tipo particular de escrita. Com isso, é possível afastar uma série de equívocos que costumam estar presentes na escola em relação aos textos literários, ou seja, tratá-los como expedientes para servir ao ensino de boas maneiras, dos hábitos de higiene, dos deveres do cidadão, dos tópicos gramaticais, das receitas desgastadas de 'prazer do texto', etc. Postos de forma descontextualizada, tais procedimentos pouco ou nada contribuem para a formação de leitores capazes de reconhecer as sutilezas, as particularidades, os sentidos, a extensão e a profundidade das construções literárias.

É notável a valorização da Literatura no documento enquanto área de conhecimento a ser trabalhada na escola. Também se percebe a crítica daqueles que utilizam um texto literário como pretexto para ensinar conteúdos gramaticais, porém não como fonte de conhecimento e reflexão ou entre tantos outros elementos importantes que a literatura pode fornecer ao leitor.

Nesse sentido, ao promover a leitura de textos literários na sala de aula, segue-se a ideia de Bakhtin, percebendo a importância de se trabalhar a língua em suas mais variadas maneiras, sabendo-se que é por meio dos gêneros que as pessoas se comunicam. Para Bakhtin (2003 [1952 - 1953]):

A língua materna - sua composição vocabular e sua estrutura gramatical - não chega ao nosso conhecimento a partir de dicionários e gramáticas, mas de enunciações concretas que nós ouvimos e nós reproduzimos na comunicação viva com as pessoas que nos rodeiam. Assimilamos as formas da língua somente nas formas das enunciações [enunciados] e justamente com essas formas. As formas da língua e as formas típicas de enunciados, isto é, os gêneros do discurso, chegam à nossa experiência e à nossa consciência em conjunto e estreitamente vinculadas. Aprender a falar significa aprender a construir enunciados (porque falamos por enunciados e não por orações isoladas e, evidentemente, não por palavras isoladas.).

Diante disso, pode-se dizer que o estudo da língua se refere a um aspecto discursivo em que a ideia transmitida é a de uma língua viva, isto é, ela age pelo real uso da interação, como o texto literário, que não pode ser reduzido, na prática pedagógica, para apenas 
estudar as formas gramaticais, tirando todo o significado do texto.

O texto literário, "Como qualquer obra de arte, oferece a possibilidade, dentro de uma relação dialógica, de cultivar espaços constantes de recriação e reformulação interior a partir do confronto autor - obra - interlocutor". (PACHECO, 2004, p. 214). Destarte, é necessário elaborar melhor a prática que envolve a leitura e a produção textual, porque, quando se trabalha na perspectiva discursiva, isso requer organização das palavras como possibilidades de construção de sentidos para que isso possa ser uma fonte interessante para o desenvolvimento do letramento,

Portanto, é relevante que a escola reserve espaços para usufruir da literatura, que, muitas vezes, fica esquecida, pois "exige tempo, atenção, concentração, luxos ou esforços que não condizem com a vida cotidiana atual”. (PERRONE-MOISÉS, 2003, p. 178). É preciso transformar as atitudes em relação à prática da leitura nas escolas, porque a sua apropriação se faz necessária para a construção do cidadão letrado.

\section{ETAPAS DO TRABALHO}

As atividades de leitura e produção textual no uso do gênero histórias sobre bruxas, lendas brasileiras e notícias de jornais; incluindo algumas brincadeiras, foram propostas pedagógicas que procuraram difundir a cultura da cooperação em várias disciplinas. Sendo assim, 17 turmas (na escola, aproximadamente, 350 estudantes do Ensino Fundamental II puderam usufruir de momentos significativos de leitura e produção de texto. As atividades foram divididas em etapas e desenvolvidas durante as aulas de Língua Inglesa e Matemática por, aproximadamente, 25 horas/aulas, na E. E. B. Natálio Vassoler, nos meses de agosto, setembro e outubro de 2013.

Destarte, as atividades iniciaram-se a partir do convite e sensibilização aos estudantes da turma 809 para estabelecer as ações e tornar a proposta viável. Uma vez aceito, partiu-se para leitura do livro: Lendas Brasileiras para jovens, do autor Luís Câmara Cascudo, e troca de informações com outros colegas da escola. Logo, eles fizeram uma pesquisa sobre o histórico do Halloween e fatos da cultura brasileira e a leitura de histórias sobre bruxas ${ }^{(1)}$, entre outras.

Na sequência, houve leitura de notícias de jornal, recriação da história, descrevendo-a a partir de aspectos dos personagens ${ }^{(2)}$ e fatos fantasiosos e, posteriormente, o envio da história para outras turmas a lerem. Outra etapa foi a confecção dos cartazes com os símbolos do Halloween, como, por exemplo, vela, caldeirão, vassoura, moeda, aranha, doces/travessura, maçã, bruxa, vampiro, abóbora, gato preto, esqueleto, fantasma, morcego, bilhete e sapo, para enfeitar as portas das salas de aula da escola. E, para finalizar, comemorou-se o dia das bruxas - Halloween, com apresentação de teatro e outras

\footnotetext{
${ }^{1}$ Histórias sobre bruxas escritas por Valerie Thomas e Korky Paul: Winnie e o dragão da meia-noite; Winnie volta a voar; Feliz aniversário, Winnie!; Winnie, a bruxinha; Winnie e o inverno; Winnie na praia; $O$ novo computador de Winnie e A varinha mágica de Winnie.

20 nome, idade, gênero, ocupação, manias, dores, tristezas, alegrias, medos, valores, atitudes admiradas, situações difíceis que enfrentou.
} 
atividades feitas durante a referida proposta.

Vale salientar que os livros que fizeram parte do repertório das leituras fazem parte do acervo da biblioteca escolar e as atividades foram organizadas com o objetivo de ampliar habilidades de leitura e produção textual de forma descontraída, sem se preocupar com a estrutura do texto ou com a decodificação das palavras. O interesse seria efetuar a compreensão do seu significado, criando uma interação entre texto/leitor e como resposta ao discurso do autor, que, segundo os PCNs (1997, p. 53):

A leitura é um processo no qual o leitor realiza um trabalho ativo de construção do significado do texto, a partir dos seus objetivos, do seu conhecimento sobre o assunto, sobre o autor, de tudo o que sabe sobre a língua: característica do gênero, do portador (livros, revistas, jornais), do sistema de escrita, etc. Não se refere apenas a extrair informação da escrita, decodificando-a letra por letra, palavra por palavra. Trata-se de uma atividade que implica, na verdade a compreensão na qual os sentidos começam a ser constituídos antes da leitura propriamente dita.

Sendo assim, conforme mencionado nesse documento, para que o aprendizado da leitura se efetue é preciso que o estudante mantenha-se próximo dos materiais escritos. Nesse caso, o estudante/leitor deve criar uma postura sistemática para ter um melhor entendimento sobre aquilo que lê, pois a compreensão do texto dará subsídios para compreender a mensagem lida, tanto oral como escrita, e para a construção de seu próprio conhecimento.

\section{AVALIAÇÃO DA EXPERIÊNCIA REALIZADA NA ESCOLA}

A avaliação dessa experiência foi feita por meio de registros escritos pelos estudantes que participaram das atividades e possibilitou uma análise dos momentos de leitura e as contribuições da oportunidade oferecida em relação a sua formação enquanto leitores.

Os professores participantes também fizeram uma avaliação a respeito das ações aplicadas, levando em consideração os registros feitos durante todos os procedimentos. Assim, foi necessário realizar uma observação criteriosa que permitiu fazer a comparação entre os objetivos definidos no projeto aos resultados alcançados ao final das atividades propostas.

Durante a realização das atividades de leitura e produção textual, perguntou-se aos estudantes qual a percepção que eles tiveram sobre os momentos de leitura, escrita e brincadeiras que aconteceram na escola.

De acordo com suas respostas, notou-se que a maioria dos estudantes gostou de participar das atividades de leitura e declarou ser muito interessante. Eles apreciaram a oportunidade que receberam e que lhes ajudou a melhorar a leitura, pois é uma forma de aprender mais, conforme dito por TS807(3): "Tive uma ótima percepção, pois é um trabalho de leitura e ajuda muito na aprendizagem dos alunos." e MI804, que disse "Eu acho que esse projeto pode nos ajudar a melhorar na leitura e pode fazer alguns alunos a gostarem

\footnotetext{
${ }^{3}$ Os nomes são fictícios para preservar a imagem do estudante.
} 
de ler livros. Eu, o primeiro livro que eu li foi um livro da escola, e eu adorei, e isso me ajudou em Português".

O trabalho realizado ajudou a gostar de ler histórias e notícias, pois, segundo AL807: "ajudou bastante porque as pessoas falavam das histórias e você fica curioso para saber o final e aí lê mais"; e para Bl807, "Sim, fui ler e me interessei mais, e soube coisas interessantes, e gostei... já me interessava por algumas coisas, mas não lia por relaxamento. AS75 reconheceu que nesse momento eles receberam mais incentivo e oportunidade para ler. O JU percebeu que "os alunos começaram a ler melhor" e a GB62, IM62 e AL65 disseram que "antes não lia muito, mas agora eu leio mais". O estudante JO75 declarou que "as lendas tem terror e nós gostamos de terror e nos deu uma motivação a mais em ler". Já, o LU74 relacionou essa oportunidade com o estudo realizado em outras disciplinas, "pois já tínhamos trabalhado o tema folclore em Geografia, Português, Artes e História". E, ainda, alguns conseguem viajar pelas palavras enquanto lê, conforme dito por WY65: "ajudou porque mostrou para mim que lendo a gente pode se transportar para outros lugares.

A maioria dos estudantes percebeu que foi uma oportunidade para conhecer novos escritores porque "cada vez que lemos, conhecemos mais", conforme dito por LU74. E para JO75, "conhecemos um escritor que nunca tínhamos ouvido falar"; e a BI807 mencionou que lia apenas as notícias e não lia o que havia escrito.

Questionou-se, também, se as oportunidades de leitura desenvolvidas na escola favorecem na sua formação enquanto leitores. A maioria respondeu que sim, pois incentiva a ler e educar mais os alunos, conforme dito por TA807; e, para AL807, um momento reservado à leitura "ajuda porque a pessoa com as histórias novas quer conhecer outras histórias e gosta cada vez mais de ler". E o estudante JO61 mencionou que há vários livros e "você pode ler todos..."

A MI804 percebeu que a leitura "ajuda muito além de me ajudar a ler melhor eu também escrevo e pronuncio as palavras melhor". Isso se comprova também pela resposta de CA74, que disse: "cada vez que lemos conhecemos mais". Assim, o WY65 também percebeu que foi possível aprender que a leitura é importante para a formação social e acrescentou "a gente aprende a escrever melhor e falar melhor também".

Pelo visto, segundo relato da maioria dos alunos, a oportunidade de desenvolver momentos para praticar a leitura na escola deve continuar porque "cada vez que o aluno aprende mais, expõe suas ideias e escreve o que entendeu", CA74; Para TA 807, é uma ótima ação para os alunos lerem melhor e Bl807 também gostaria que continuasse, pois "eu me interessei muito, foi uma aula diferente, foi muito legal". Outros estudantes GI61, JO61, G162 e IM62 inclusive sugeriram outros temas para trabalhar em novos projetos, como: trânsito, esporte, primavera, música etc.

Perguntou-se, também, aos professores que participaram sobre a percepção que eles tiveram diante dos momentos de leitura, escrita e brincadeiras na escola. 
Assim a professora $\mathrm{CV}^{(4)}$ mencionou que eles já costumam fazer bastante leitura com livros da biblioteca em sala de aula nas várias disciplinas, como: Português, História, Geografia, Artes etc; A professora CR disse "percebi um maior entusiasmo dos alunos pela atividade de leitura e produção textual, por se tratar de uma novidade proposta pela professora" e as professoras VF e ML afirmaram que "A metodologia usada foi bastante significativa para as turmas. Onde os alunos começaram a ter mais interesse na leitura".

Os professores concordam que esse momento seja uma oportunidade para conhecer novos escritores e, conforme dito pela professora CR, "Isso ajuda ao professor a conhecer novos talentos na arte da escrita".

Esses professores também perceberam que um trabalho que envolve a leitura sempre ajuda o estudante a gostar mais de ler, pois, segundo CR, "Sempre que há atividade inovadora percebe-se mais interesse por parte dos alunos". Na visão de VF e ML, os alunos ficaram motivados e elas notaram, também, que "a partir da reconstrução da história, com teatros, teatro de vara e teatro de fantoche; leitura no pátio, na biblioteca e leitura coletiva".

Sendo assim, os professores participantes das atividades afirmaram que seria importante dar continuidade às propostas de leitura e produção textual na escola porque é uma forma de aguçar o gosto pela leitura, conforme mencionado por CR. Nesse sentido, as professoras VF e ML perceberam que um trabalho desse tipo enriquece cada vez mais o processo ensino aprendizagem, despertando o interesse e a motivação dos alunos.

\section{CONSIDERAÇÕES COMPLEMENTARES}

O referido trabalho teve como enfoque a leitura de histórias de bruxas, lendas brasileiras, notícias de jornais e brincadeiras, buscando uma articulação entre os estudantes do Ensino Fundamenta II da referida escola, no sentido de disseminar a cultura da cooperação, na sala de aula, por meio de um tema, Halloween, solicitado pelos estudantes da turma 809.

Essa proposta se configurou, também, como uma contribuição à formação de leitores e a habilidade de produção textual escrita de uma maneira descontraída. Pode-se dizer que foi possível ampliar o conhecimento sobre uma cultura estrangeira, que, ao mesmo tempo, é comemorada no Brasil por meio da leitura de histórias, lendas e notícias. Os estudantes puderam ler alguns livros, ouvir a leitura feita pelos colegas, ou seja, eles puderam experimentar o deleite pela leitura em várias situações de uma forma cooperativa, nas quais cada um procurou ajudar e respeitar os limites dos colegas na sala de aula;

Os estudantes conseguiram relacionar as histórias lidas, manifestando seus sentimentos, experiências, opiniões, definindo preferência e construindo critérios próprios para selecionar o que querem ler e, inclusive, produzindo os próprios textos e encaminhando-os aos colegas de outras séries na escola.

\footnotetext{
${ }^{4}$ Os nomes dos professores que fizeram avaliação são fictícios.
} 
Afirma-se, então, que essa proposta tornou-se importante para a instituição escolar porque os próprios estudantes declararam a sua satisfação, em relação ao aproveitamento e real aplicabilidade no contexto em que eles participam como meio de formação educacional.

Assim, ficou evidente que as atividades de leitura e produções textuais desenvolvidas na sala de aula promoveram uma atitude de cooperação na sala de aula, visto que sempre havia necessidade de atuar em parceria com os colegas. Nesse caso, os estudantes, principalmente os da turma 809 que desenvolveram o trabalho, tiveram maior envolvimento junto às atividades feitas na sala de aula.

Cabe salientar que, quando eles sentiam dificuldades ao fazerem as leituras e suas produções, um ajudava o outro a realizar a tarefa proposta. E, ainda, confirmou-se, pela atitude desses estudantes que trabalharam junto à professora organizadora, que a prática de leitura e escrita tornou-se um meio para amenizar algumas situações difíceis que envolvem a falta de vontade de fazer as tarefas, o desânimo nas aulas, relacionamento, falta de respeito e até situações de violência na escola, isto é, obstáculos enfrentados diariamente no contexto escolar.

\section{REFERÊNCIAS}

BAKHTIN, M. Marxismo e filosofia da linguagem. Trad. Michel Lahud e Yara Frateschi Vieira. São Paulo: Annablume, 2002.

Os gêneros do discurso. In: Estética da Criação Verbal. Trad. Paulo Bezerra. São Paulo: Martins Fontes, 2003.

BRASIL. Secretaria de Educação Fundamental. Parâmetros curriculares nacionais: Língua Portuguesa. Brasília: MEC/SEF, 1997.

Parâmetros curriculares nacionais: Língua Portuguesa. Brasília: MEC/SEE, 1998.

PACHECO, P. da S. A linguagem literária em tempos de crise. In: APARECIDA et al. Democratizando a leitura: pesquisas e práticas. Belo Horizonte: Autêntica, 2004.

PERRONE-MOISÉS, L. Altas literaturas. São Paulo: Cia. das Letras, 2003.

SOARES, M. B. Leitura e Democracia Cultural. In: APARECIDA Paiva et al. Democratizando a Leitura: pesquisas e práticas. Belo Horizonte: Autêntica; 2004a.

Letramento: um tema em três gêneros. 2. ed. Belo Horizonte: Autêntica, 2004b. 